\title{
Short-Term Fluctuations Reason Analysis of Exchange Rate Based on Microeconomic
}

\author{
LUO Xiao \\ Economics and Management School, Sichuan University of Science \& Engineering, Zigong, \\ Sichuan 643000, China \\ 9496465@qq.com
}

Keywords: Exchange rate fluctuations; Private information; Heterogeneity; Trading mechanism

\begin{abstract}
The traditional model of exchange rates, which use macroeconomic variables as its determinants, cannot give a good explanation of short-term fluctuations in the exchange rate. The main reason is there are some implied assumptions in the model, such as public information, the same investors and independent of the trading system. In this paper, in order to understand better and explain the fluctuations reason of short-term exchange rate, the corresponding analysis of short-term fluctuations in exchange rate is made base on microeconomic.

The international monetary system entered floating exchange rate era, after the collapse of the Bretton Woods system in 1970s. For the reason that these models use macroeconomic variables as its determinants and there are some implied assumptions, such as public information, the same investors and independent of the trading system, are impractical, the traditional exchange rate determination theory (purchasing power parity, interest rate parity, etc.) and the exchange rate model cannot give a reasonable explanation about the volatility of the exchange rate. So using microeconomic analysis, weaken the assumptions and make corresponding analysis the influence and the reason about foreign exchange markets on exchange rate changes under non-rational expectations or incomplete information are considerable practical significance. To do microeconomic analysis, we need three assumptions which is the premise of exchange rate fluctuation. 1) Existence of private information. 2) Heterogeneity of the participants in foreign exchange markets. 3) The importance of trading mechanism. We will analyze the causes of exchange rate fluctuations from the three aspects.
\end{abstract}

\section{Private Information and Exchange Rate Fluctuations}

In the traditional exchange rates decision, the macroeconomic model is built based on the information publicity. That means all traders in the foreign exchange markets can share the same information. But according to the market microstructure theory, the main influencing factors of exchange rate fluctuations are the effects on trades and prices caused by the incomplete information. So the basis is private information, it is considered as the key to the formation of prices. The private information has the following two distinctive features: 1) It cannot be shared by all traders. 2) It is better to predict future price movements than the public information. The most typical example of the existence of private information in foreign exchange markets is the intervention of Central Bank., Using the temporary information, which else traders cannot get, to get more benefit through certain foreign exchange dealers, the Central Bank can intervention in the foreign exchange markets.

There are two main types of private information. One is private information for final profit. If this type of information makes the expectation of final profits to be changed, asset prices in the financial market would fluctuate. The other private information is for the price. Sometimes the final profit of asset investment is fixed, but usually asset prices cannot be determined. Such as the international investment of financial assets should be the interest rate differential between the two countries. The price of foreign exchange can be influenced directly by the preference of investors, status of portfolio, capital management and Investors' expectations.

Now let us look at "inventory effect" and "portfolio effect". Market makers just want to accept a few orders. But in order to improve the liquidity of orders in the market, they have to accept a lot of 
orders by low price. This make them to take exchange rate risk which bring by the asymmetric market supply, for there are lots of short orders come out in the market. The storks are hold by the merchants, but the difference price of buyers and sellers is widening, which cannot be removed until the balance of market supply and demand is regained. This is called inventory effect of market makers. In another case, the expected of exchange rate on market has changed which lead the investors alter the portfolio and adjust the trading orders. In this case the difference price of buyers and sellers cannot be recovered immediately. We call this reason by which the price changes caused is "portfolio effect".

In a word, the price volatility of the foreign exchange markets most probably caused by the effect of private information. The different reason to form the private information always cause the different duration of the impact on the price. So the degree and frequency of price fluctuations are always different.

\section{Heterogeneity of Traders and Fluctuations of Exchange Rate}

Large numbers of research have shown that to demonstrate the efficient market hypothesis (risk-neutral and the assumption of rational expectations) by the exchange rate is not right. Some economists believe, heterogeneity expectation make the efficient market hypothesis cannot be established, which is the main reason the traditional exchange rate theory cannot explain why the real exchange rate fluctuates.

\subsection{Trading motives of participants are different}

There are two kinds of investors in foreign exchange markets. One is speculators for asset appreciation; the other is risk aversion hedgers. For the objective functions of speculators and hedgers are different, the exchange rate fluctuations will comes out if the interaction of them are inconsistent with the model description. Stoll (2012) pointed out in his literature review on market structure that speculators typically use active investment strategy. They usually use the traditional methods of market introductions, that is money concentrated in one or a few assets which considered as a good income. But hedgers typically use negative investment strategy. They usually use the limited price traditional way. That is money dispersed in multiple income-irrelevant assets. So speculators need to be instantaneous for they hope the price is suitable for their trading. And to keep the instantaneous of providers is better for the price stability. The cause of such difference between speculators and hedgers is due to the ways they deal with the information and the formed expectations based on this.

\subsection{The ways by which participants to analysis of the information are different}

Based on the expected heterogeneity of market participants some economists use the noise trader model to instead of the efficient market hypothesis. There are two kinds of traders in the noise trader model. They are smart investors and noise traders. Smart investors are the rational maximized investors, whose transactions based on economic fundamentals, which can prevent the exchange rate to deviate from economic fundamentals and promote the exchange rate back to the level of determined by economic fundamentals. But noise traders are irrational, whose transactions based on the noise information, which is nothing to do with the economic fundamentals. Their behavior would lead to the exchange rate deviate from economic fundamentals. The existence of irrational traders in market transactions leads to two cases in the market. One is every traders may consider the useless information as the information associated with the value. This case is existed in any market. The other case is some false information is made by some traders, which may lead other traders make wrong decisions. But in this case the noise trading can be avoided. With the floating exchange rates, the presence of noise traders may cause the multiple equilibriums of the foreign exchange markets. The greater the exchange rate fluctuations, the more noise traders would join in the market. And the more participators of noise traders would lead to the greater exchange rate fluctuations.

\subsection{The information of market investors is asymmetric}

The key factors with which investment behavior of investors are affected are the private information they get. Although market makers control the operation of the market and they can set 
the price, the result of strategy by which informed traders and uninformed traders are used interact with the market participants' strategy will ultimately affect on the pricing mechanism of market maker. Frankel and Froot (1987) emphasize that the heterogeneity of investors base on asymmetric information, which makes the informed traders get more profit, but uninformed traders lose the profit. In a word, information in foreign exchange markets are different from the information in stock market (every participant has the information in all companies). Transaction information is consisting of the trading information of investors in foreign exchange markets, which some traders can get but others cannot. Whether the investors can get this information have a significant impact on the trading price.

\section{Trading Mechanism and Exchange Rate Fluctuations}

There are two obvious characteristics of foreign exchange markets. One is, it is a huge two-tier structure fragmented markets, that means customers transact business with banks and banks transact business with banks. The other is, the huge amount of transactions in the foreign exchange market is determined by the market maker mechanism. Traders can select the direct inter-bank transactions form, and also can choose indirect transaction form of using a broker intermediary. Lyons (2001) pointed out special structure of foreign exchange trading system is closely related to failure of validation in foreign exchange markets.

\subsection{Amount of transactions and exchange rate fluctuations}

Every day, there are great amount of transactions in the foreign exchange markets. According to the statistics of the Bank for International Settlements, after the New Year festival the rapid expansion of the transactions in foreign exchange markets is far more than the deed of actual investment and trade. Now, just 4 percent of the spot foreign exchange transactions are related to the trading. But exchange rate standard macro model does not include the amount of foreign exchange transactions, but that it has nothing to do with the exchange rate fluctuations, which is a major drawback, and may even lead to the mistaken explanations of standard macroeconomic models to explain the reality phenomenon.

Philippe Jorion tested the market microstructure theory of exchange rate fluctuations proposed by Tauchen and Pitts (1983), and got the following inference. When the number of transactions are determined is determined by a variety of traders, that means the number of transactions are determined from heterogeneous, the amount of transactions are positively correlated with exchange rate fluctuations; when the number of transactions are determined by the major traders, the amount of transactions and exchange rate fluctuations negatively correlated. Trading noise, which may lead to excessive volatility in exchange rates, were found by French and Roll (1986). They found that even when the market closed on Election Day or other special day fluctuations is continued rather than to be interrupted until the next opening, that is fluctuations inertia. Fluctuation is mainly affected by the impact of transactions, under the same conditions in the flow of information. Frankel and Froot (1988) pointed transactions and changes in the spot exchange rate are highly correlated. Lyons (1995) did a lot of research of the foreign exchange market microstructure assumptions, and would like to test the effect of the transactions by using the offer information and the control of inventory. The results show that the amount of transactions is indeed affect quotations through these two ways at the same time. Lyons examined the effect of amount of transactions on the exchange rate, and put forward two theories about the reason why there exist a larger number of transactions. One is the uncertainty of the event. A larger number of transactions are caused by the rapidly processed information. Market participants to determine whether there exists private information through the number of transactions. If there are a few transactions in the markets, it means that there is no influence information on the exchange rate exists in the markets. So the market will be relatively calm. On the contrary, if there are large amounts of transactions, it means that there exists positive information. So the amount of transactions will be further amplified by the traders. The other one is "hot potato" theory. Large amount of transactions is because the information is hardly to be treated. That is mobility investors give the orders to the brokers who sell excess positions to them, and the positions of foreign exchanging are transmitted like hot potatoes. 
It is confirmed that the hot potato theory is right. The number of transactions has a major impact on the exchange rate in the longer time transactions, and the number of transactions has a less affect on the exchange rate in the shorter time transactions.

\subsection{Concentration of foreign exchange market and fluctuations of exchange rate}

From the current situation of the spot foreign exchange transactions, we knew inter-bank transactions and transactions through the brokers occupy almost all the percentage in foreign exchange transactions. The number of transactions through the brokers continues increase. The general view of the trading mechanism is, market brokers can use more efficiently of time to rapid elimination of a large number of arbitrage opportunities, through centralized trading and collecting price information, and also to ensure the instructions of traders executing normally according to the principle of price priority. In the early microstructure theory of the foreign exchange markets, it is shown that the differences of market concentration degree may be very important to explain the difference of the market performance. Flood (1994) had did a simulation experiments to examine the operating efficiency of the U.S. foreign exchange market within a trading day, through a special market structure which includes a market makers, brokers and customers. His conclusion is centralization is a key factor to achieve efficiency markets. He found a large number of inefficient operations in the market can be explained by the inherent temporary inventory imbalances in the fragmented markets. And the inherent temporary inventory imbalances can greatly reduce this inefficiency by centralizing price information. But in 1996 Perraudin and Vitale constructed a fine theoretical framework for decentralized transaction markets, and discuss the meaning of efficiency and the prices information transmission mechanism of the foreign exchange market. They pointed out why the large number of transactions between operators rather than customers is because of the diversified foreign exchange markets. Every investor cannot know trading instructions. Some traders can get useful information from the customer's instructions, but other traders cannot.

\section{Conclusion}

All in all, due to the presence of private information, the heterogeneity behavior of traders and the trading mechanism will have a major impact on the short-term fluctuations in the exchange rate. Therefore, it is not enough to analyze the reason of the fluctuations in the exchange rate only from the perspective of macroeconomic, we must introduce the analysis on the market microstructure, give a deep discussion on the fluctuations in the exchange rate from the perspective of microeconomic. Meanwhile, with the development of information economics, transaction cost theory and game theory, etc, it is believed that the theory of explaining the movement of real exchange rate from the perspective of microeconomic will have a good development in exchange rate prediction and market design.

\section{References}

[1] ZHAO Yuping, ZHANG Jidong: Microstructure analysis on the Theory of Exchange Rate Fluctuation, A Survey. Contemporary Economy and Management, vol. 28(2006), p. 90-94.

[2] ZENG Zhenyu: Microscopic Interpretation of the Fluctuations in Short-term Exchange Rate, Shanghai Financial, vol.6( 2003), p. 40-42.

[3] XI Junyang, ZHANG Zhenyu: The Microscopic Analysis of Exchange Rate Formations, Guangdong Social Sciences, vol. 1(2005), p. 54-57.

[4] LV JiangLin, WANG Lei: The Developmental Skeleton Commentary on the Theory of Exchange Rate Determination, Jiangxi Social Sciences vol. 7(2009).

[5] LI Jie: Developmental Research on the Theory of Exchange Rate Determination, Theoretical Investigation, vol. 1(2010).

[6] LI Xiaopin: New Developments on the Theory of the microstructure of Exchange Rate Determination, Economic Perspectives, vol. 7(2008).

[7] Vitale,P."A guided tour of the market microstructure approach to exchange rate determination". Journal of Econometrics. (2007)

[8] Laakkonen,H,M.Lanne."Asymmetric news effects on volatility:Good vs.bad news in good vs.bad times". MPRA Paper No 8296. (2008) 